\title{
Fabrication and Characterization of Antibacterial-active Multilayer Films Based on Keggin Polyoxometalates and Methylene Blue
}

\author{
Dan Chen ${ }^{\mathrm{a}}$, Jun Peng a , Haijun Panga ${ }^{\mathrm{a}}$, Pengpeng Zhang ${ }^{\mathrm{a}}$, Yuan Chen ${ }^{\mathrm{a}}$, Yan Shen ${ }^{\mathrm{a}}$, \\ Changyun $\mathrm{Chen}^{\mathrm{a}}$, and Huiyuan $\mathrm{Ma}^{\mathrm{b}}$ \\ a Key Laboratory of Polyoxometalate Science of Ministry of Education, Faculty of Chemistry, \\ Northeast Normal University, Changchun, Jilin, 130024, P. R. China \\ b Department of Chemistry, Harbin Normal University, Harbin 150080, P. R. China \\ Reprint requests to Dr. Jun Peng. E-mail: jpeng@nenu.edu.cn
}

Z. Naturforsch. 2010, 65b, 140 - 146; received November 5, 2009

\begin{abstract}
Two kinds of multilayer films based on Keggin polyoxometalates $\alpha$ - $\left[\mathrm{SiW}_{12} \mathrm{O}_{40}\right]^{4-} / \alpha$ $\left[\mathrm{PMo}_{12} \mathrm{O}_{40}\right]^{3-}$ and methylene blue have been prepared via the layer-by-layer (LBL) self-assembly technique. The multilayer films were characterized by UV/Vis spectra, atomic force microscopy (AFM) and X-ray photoelectron spectra (XPS). The cyclic voltammetry (CV) measurements have demonstrated that the electrochemical properties of POMs are maintained in the LBL films. The antibacterial activity of the LBL films has also been investigated, which shows a distinct antibacterial effect against Escherichia coli.
\end{abstract}

Key words: Thin Films, Polyoxometalates, Methylene Blue, Atomic Force Microscopy, Antibacterial Activity

\section{Introduction}

Polyoxometalates (POMs) as a significant class of nanoclusters with much diversity in composition, size and function have been extensively investigated in the development of various fields, such as biology, medicine, catalysis, and materials science [1-4]. When POMs are used to assemble to ultrathin films, their virtue will be incorporated into the films, and the application of POMs will become convenient and advantageous [5-8]. Layer-by-Layer (LBL) selfassembly is a simple but impactful technique to prepare uniform multilayer films. It can precisely control the composition, thickness, and orientation of each layer on the molecular level, offering potential advantages for thin film materials in molecular electronic devices [9-11]. Owing to these advantages, the LBL deposition of POMs with oppositely charged polyelectrolytes has been widely investigated, and various functional ultrathin films based on POMs have been fabricated, such as photoluminescent ultrathin films [12,13], electrochromic films $[14,15]$, photochromic multilayer films $[16,17]$, electrocatalytic ultrathin films $[18,19]$, and so on. In these POM-based ultrathin films, surfactants, metal complex cations and polycations were introduced as the oppositely charged composites. LBL films combining cationic dye molecules with POMs have also been systematically investigated regarding their thermal and photochemical stability by $\mathrm{Cao}$ and co-workers [20].

Methylene blue $(\mathrm{MB})$ is a dye molecule $\left(\mathrm{C}_{16} \mathrm{H}_{18}\right.$ $\mathrm{ClN}_{3} \mathrm{~S}$ ) widely found in living organisms, and its main function is electron transport in different biological processes [21]. MB with natural antifungal and antibacterial activity has attracted considerable attention due to its application in photodynamic therapy for the selective killing of bacteria, fungi, viruses, and cancerous cells [22-25]. It exists as a cation in neutral and alkaline solution. Therefore, it is a good candidate to assemble the film materials which can provide a bacteriostatic surface acting as disinfectant and sterilizer.

In this paper, we describe the preparation and characterization of nanocomposite ultrathin films based on the classical Keggin POMs $\alpha$-[ $\left[\mathrm{SiW}_{12} \mathrm{O}_{40}\right]^{4-},(\alpha-$ $\left.\mathrm{SiW}_{12}\right) / \alpha-\left[\mathrm{PMo}_{12} \mathrm{O}_{40}\right]^{3-},\left(\alpha-\mathrm{PMo}_{12}\right)$ and $\mathrm{MB}$ (shown in Fig. 1) by the LBL technique. Their antibacterial activity is reported for the first time. Notably, the LBL POMs/MB films show not only good stability and reproducibility, but also obvious inhibition effects on the growth of Escherichia coli (E. coli). 


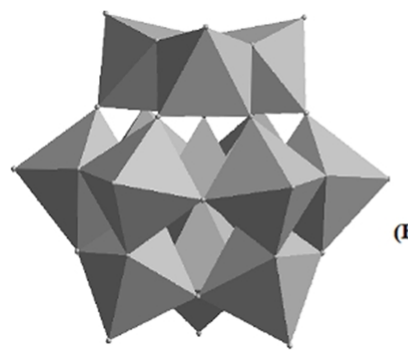

$\left(\mathrm{H}_{3} \mathrm{C}_{2} \mathrm{~N}\right.$
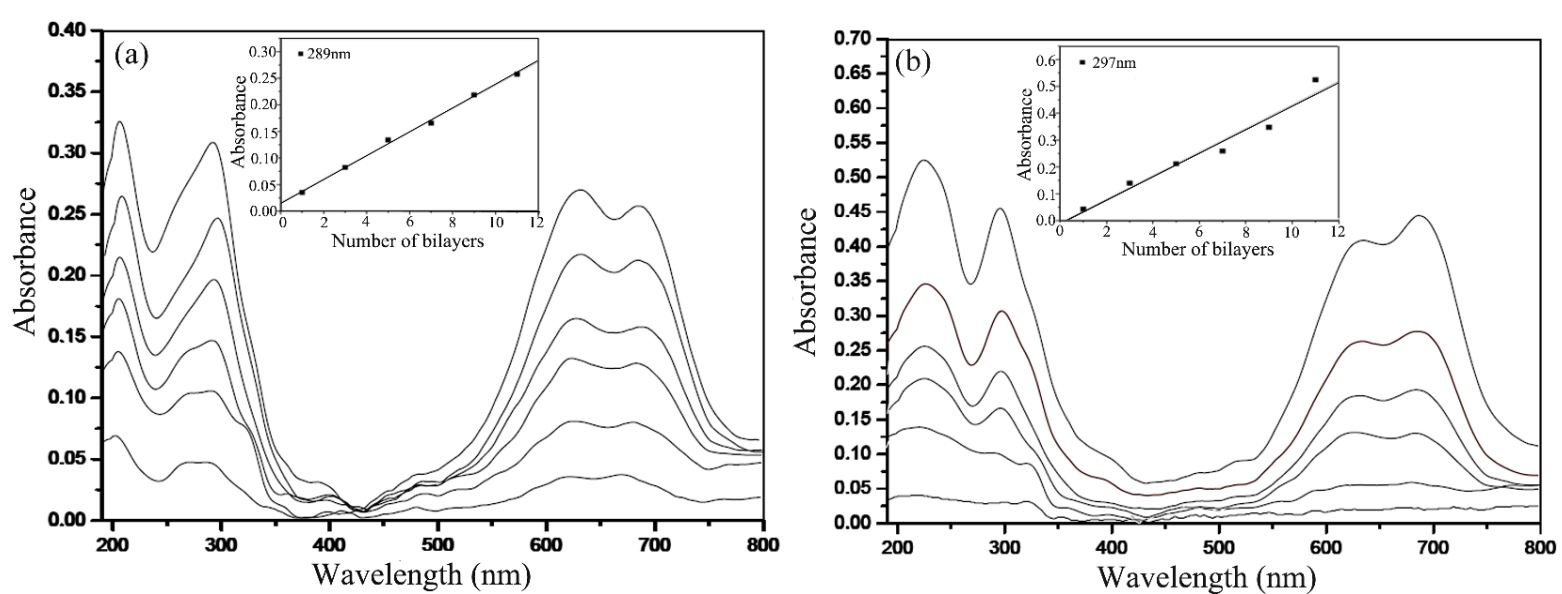

Fig. 2. UV/Vis absorption spectra of $\left\{\mathrm{PEI} /\left(\alpha-\mathrm{SiW}_{12} / \mathrm{MB}\right)_{n}\right\}$ (a) and $\left\{\mathrm{PEI} /\left(\alpha-\mathrm{PMo}_{12} / \mathrm{MB}\right)_{n}\right\}$ (b) (with $\left.n=1,3,5, \ldots\right)$ assembled on a quartz substrate (on both sides). The insets show plots of the absorbance values at $289 \mathrm{~nm}$ for (a) and $297 \mathrm{~nm}$ for (b) $v s$. the number of POMs/MB bilayers.

\section{Results and Discussion}

\section{UV/Vis absorption spectra}

The UV/Vis spectra (Fig. 2) of the multilayer films $\left\{\mathrm{PEI} /\left(\alpha-\mathrm{SiW}_{12} / \mathrm{MB}\right)_{n}\right\}$ (a) and $\{\mathrm{PEI} /(\alpha-$ $\left.\left.\mathrm{PMo}_{12} / \mathrm{MB}\right)_{n}\right\}$ (b) $(n=1,3,5, \ldots)$ exhibit the characteristic absorption peaks of the polyanions at 205 and $289 \mathrm{~nm}$ for $\alpha-\mathrm{SiW}_{12}$ and at 226 and $297 \mathrm{~nm}$ for $\alpha-\mathrm{PMo}_{12}$ which are attributed to the $\mathrm{O} \rightarrow \mathrm{W}$ and $\mathrm{O} \rightarrow$ Mo charge transfer (CT) transitions, respectively. This confirms the incorporation of POMs $\left(\alpha-\mathrm{SiW}_{12}\right.$ and $\left.\alpha-\mathrm{PMo}_{12}\right)$ into the multilayer films. The absorption peak of $\mathrm{MB}$ in the $\mathrm{UV}$ region is overlapping with the CT transitions of the POMs. In the visible region, the absorption bands at 627 and $686 \mathrm{~nm}$ can be assigned to $\mathrm{MB}$, and a steady enhancement of the absorption with the increase of the number of dipping cycles is observed. A linear increase of the absorbency value at $c a .290 \mathrm{~nm} \mathrm{vs}$. the increase of the bilayer number of the LBL films (shown in Fig. 3 insets) indicates that each adsorption cycle proffers nearly equal amounts of POMs and MB into the
Fig. 1. Molecular structures of a Keggin POM (left) and methylene blue (right). 

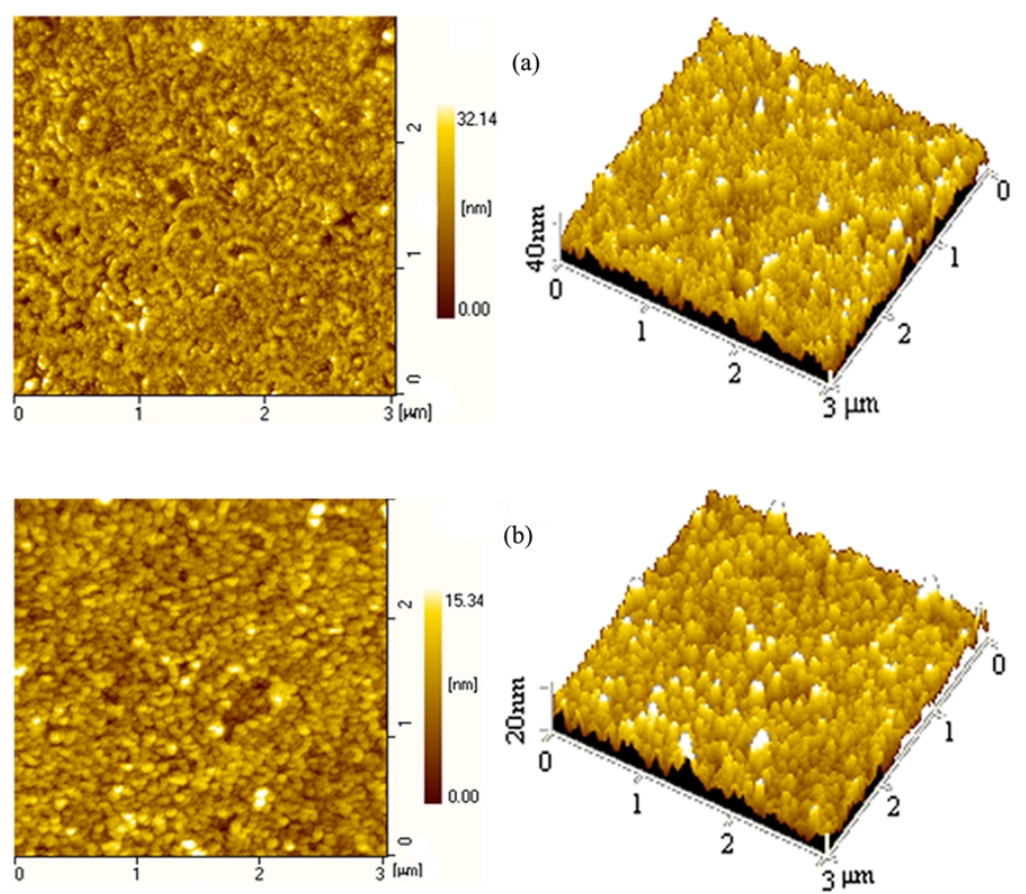

Fig. 3. AFM images of the multilayer films $\left\{\mathrm{PEI} /(\mathrm{POMs} / \mathrm{MB})_{3} \mathrm{POMs}\right\}$ $\left[\mathrm{POMs}=\alpha-\mathrm{SiW}_{12}\right.$ (a) and $\alpha-\mathrm{PMo}_{12}$ (b)] assembled on silicon substrates.

$\mathrm{W} 4 f 7 / 2(\mathrm{BE}=35.1 \mathrm{eV}), \mathrm{W} 4 f 5 / 2(\mathrm{BE}=37.3 \mathrm{eV})$, Mo3d 3/2 $(\mathrm{BE}=235.7 \mathrm{eV})$, and Mo3d 5/2 $(\mathrm{BE}=$ $232.5 \mathrm{eV})$. The $\mathrm{C} 1 s$ and the N1s signals can be assigned to the carbon and amido groups in MB and PEI, the $\mathrm{S} 2 p$ signal is ascribed to the sulfur in $\mathrm{MB}$, while the W4 $f$ signals are ascribed to $\alpha-\mathrm{SiW}_{12}$ and the Mo3d to $\alpha-\mathrm{PMo}_{12}$ polyanions. XPS results thus also confirm the existence of MB and POMs in the multilayer films in conjunction with the results of UV/Vis spectra.

\section{Electrochemical behavior of the multilayers}

The film of $\left\{\mathrm{PEI} /\left(\alpha-\mathrm{SiW}_{12} / \mathrm{MB}\right)_{n}\right\} \quad(n=10)$ undergoes three redox waves in the range from -1200 to $200 \mathrm{mV}$ with midpoint potential $E_{\mathrm{mid}}=\left(E_{\mathrm{pa}}+\right.$ $\left.E_{\mathrm{pc}}\right) / 2$ values of $-214,-543$, and $-957 \mathrm{mV}$, and the $\left\{\mathrm{PEI} /\left(\alpha-\mathrm{PMo}_{12} / \mathrm{MB}\right)_{n}\right\}(n=10)$ film also exhibits three redox waves in the range from -200 to $600 \mathrm{mV}$ with $E_{\text {mid }}$ values of 331,180 and $-43 \mathrm{mV}$. These redox processes are similar to the matrix POMs in homogeneous solution, but both show a peak shift perhaps owing to POMs in different phases (see Fig. 5). The results demonstrate that the electrical properties of $\alpha-\mathrm{SiW}_{12}$ and $\alpha-\mathrm{PMo}_{12}$ are maintained in the LBL films. Notably, the peak currents at ca. $-214 \mathrm{mV}$ for $\left\{\mathrm{PEI} /\left(\alpha-\mathrm{SiW}_{12} / \mathrm{MB}\right)_{n}\right\}$ and at $c a$. $-41 \mathrm{mV}$ for $\left\{\mathrm{PEI} /\left(\alpha-\mathrm{PMo}_{12} / \mathrm{MB}\right)_{n}\right\}$ are obviously enhanced be- cause of an overlap with the MB redox processes (Fig. 6).

\section{Antibacterial activity}

The antibacterial activity of the films against the bacteria $E$. coli was carefully assessed [26,27]. In Fig. 7, we find that the substrates 2 and $3[2=\{\mathrm{PEI} /(\alpha-$ $\left.\left.\left.\mathrm{PMo}_{12} / \mathrm{MB}\right)_{n}\right\}, 3=\left\{\mathrm{PEI} /\left(\alpha-\mathrm{SiW}_{12} / \mathrm{MB}\right)_{n}\right\}\right]$ have significant antibacterial activity with well-defined inhibiting zones (diameter $c a .30 \mathrm{~mm}$ ), while the control tests of (PEI/POMs $)_{n}$ and single monolayer PEI films show that POM and PEI have unconspicuous antibacterial activity, as uniform colonies are observed around them.

$\mathrm{MB}$ as a cation with natural antifungal and antibacterial activity is expected to inhibit the growth of $E$. coli [24], however, the control experiment with $\left\{\mathrm{PEI} /(\mathrm{PSS} / \mathrm{MB})_{n}\right\}$ shows negligible antibacterial activity. The result may be explained as below: the single-charged MB cation could not be absorbed firmly onto polyelectrolyte PSS to form highly reproducible LBL films [20], and might be eluted into PSS aqueous solution. This implies that only a small amount of MB molecules is incorporated into the $\left\{\mathrm{PEI} /(\mathrm{PSS} / \mathrm{MB})_{n}\right\}$ films. Therefore the antibacterial activity can not be brought into play, and the colonies grow orderly. POMs with high surface charge have stronger elec- 

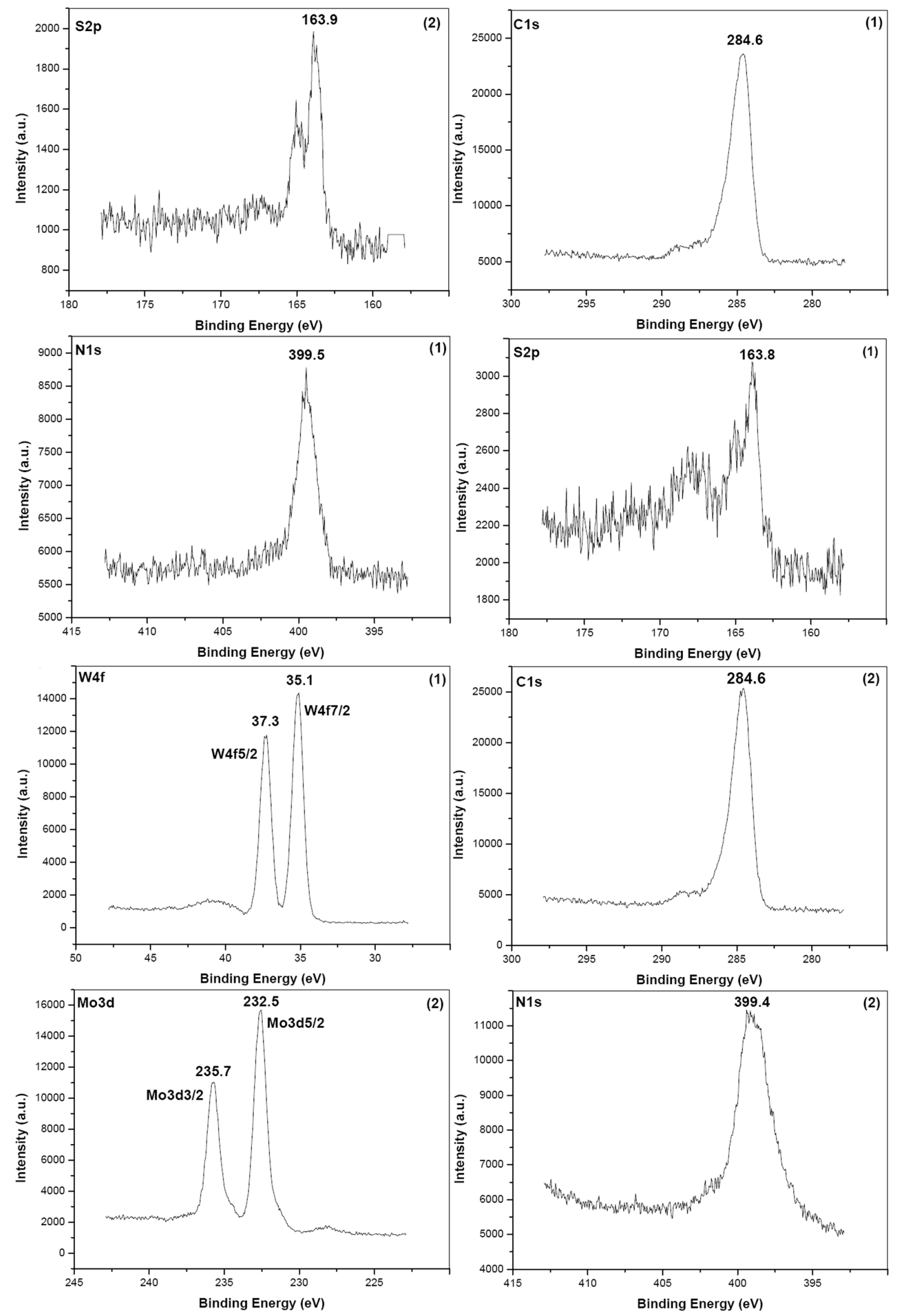

Fig. 4. The XPS spectra of the multilayer films. (1) $\left\{\mathrm{PEI} /\left(\alpha-\mathrm{SiW}_{12} / \mathrm{MB}\right)_{n}\right\}(n=7)$, (2) $\left\{\mathrm{PEI} /\left(\alpha-\mathrm{PMo}{ }_{12} / \mathrm{MB}\right)_{n}\right\}(n=7)$. 

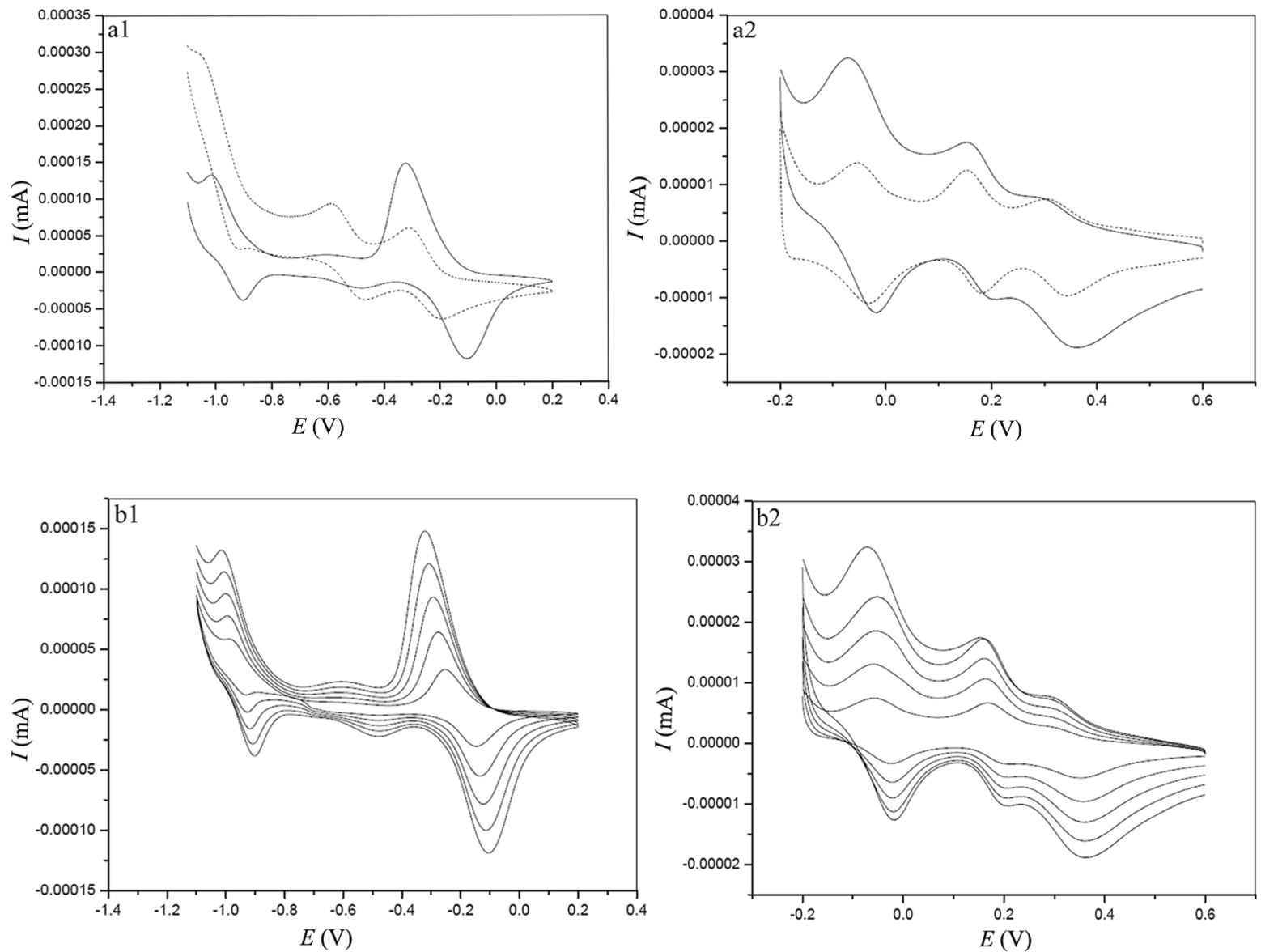

Fig. 5. Cyclic voltammograms of the bare ITO electrodes in $0.5 \mathrm{mM} \alpha-\mathrm{SiW}_{12}$ (a1) and $\alpha-\mathrm{PMo}_{12}$ (a2) in $0.1 \mathrm{M} \mathrm{HAc}-\mathrm{NaAc}$ ( $\mathrm{pH}=4.7$ ) (dotted lines), and LBL films of $\alpha-\mathrm{SiW}_{12}$ (a1) and $\alpha-\mathrm{PMo}_{12}$ (a2) on ITO electrode (solid lines) in $0.1 \mathrm{M} \mathrm{HAc-}$ $\mathrm{NaAc}(\mathrm{pH}=4.7)$ at a scan rate of $100 \mathrm{mV} \mathrm{s}^{-1}$; LBL film of $\left\{\mathrm{PEI} /(\mathrm{POM} / \mathrm{MB})_{10}\right\}\left[\mathrm{POM}=\alpha-\mathrm{SiW}_{12}(\mathrm{~b} 1)\right.$ and $\left.\alpha-\mathrm{PMo}_{12}(\mathrm{~b} 2)\right]$ on ITO electrodes in $0.1 \mathrm{M} \mathrm{HAc-NaAc}(\mathrm{pH}=4.7)$ at scan rates of $20,40,60,80$, and $100 \mathrm{mV} \mathrm{s}^{-1}$.

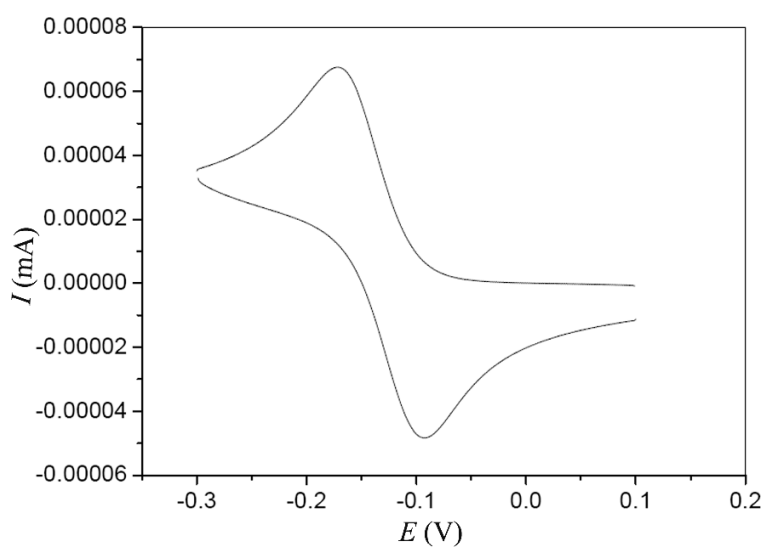

Fig. 6. Cyclic voltammogram of $\mathrm{MB}(0.05 \mathrm{mM})$ in $0.1 \mathrm{M}$ HAc-NaAc $(\mathrm{pH}=4.7)$; scan rate $100 \mathrm{mV} \mathrm{s}^{-1}$. trostatic force than the polyelectrolyte PSS. When POMs are used as polyanions to combine with MB, the MB can be absorbed substantially into the LBL multilayer films, so that the antibacterial activity of $\left\{\mathrm{PEI} /(\mathrm{POMs} / \mathrm{MB})_{n}\right\}$ films is maintained.

\section{Conclusion}

Well-behaved multilayer films based on Keggin POMs and MB were prepared through an LBL self-assembly technique. $\left\{\mathrm{PEI} /(\mathrm{POMs} / \mathrm{MB})_{n}\right\}$ multilayer films clearly exhibit antibacterial activity against E. coli, which may be due to POMs with their relatively high surface charge and the strong adsorption force to MB molecules in the LBL multilayer films. This result shows potential application of the $\left\{\mathrm{PEI} /(\mathrm{POMs} / \mathrm{MB})_{n}\right\}$ 

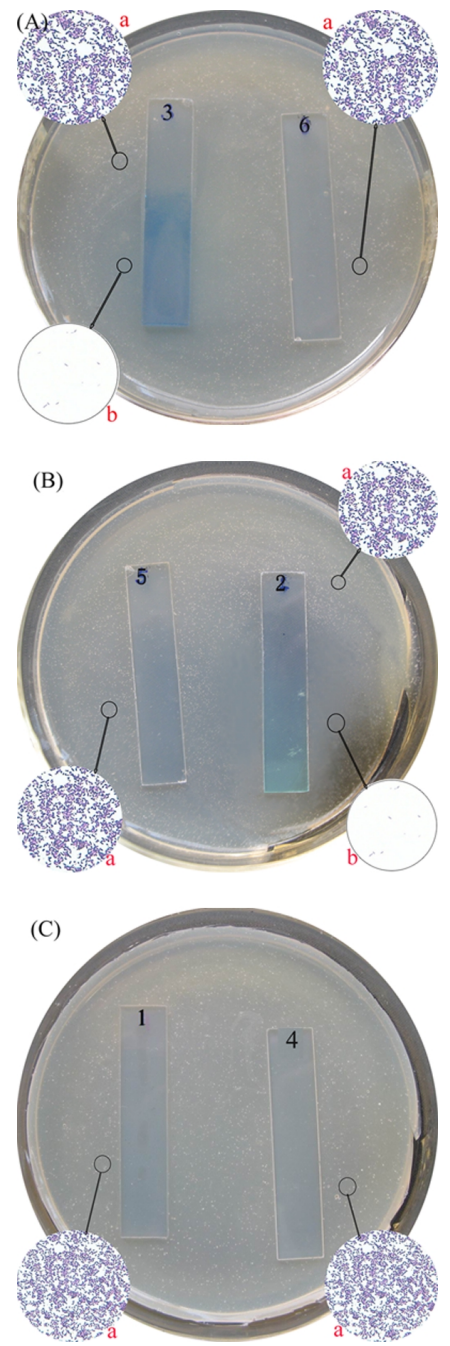

Fig. 7. Optical photographs of antibacterial tests for various LBL multilayer films. The rotundity iconographs (a) and (b) present the non-inhibition zones and inhibition zones, respectively, under the optical microscope. In picture (A), substrates $3=\left\{\mathrm{PEI} /\left(\alpha-\mathrm{SiW}_{12} / \mathrm{MB}\right)_{n}\right\} \quad(n=20)$ and $6=$ $\left(\mathrm{PEI} / \alpha-\mathrm{SiW}_{12}\right)_{n}(n=20)$, in $(\mathrm{B})$, substrates $2=\{\mathrm{PEI} /(\alpha$ $\left.\left.\mathrm{PMo}_{12} / \mathrm{MB}\right)_{n}\right\}(n=20)$ and $5=\left(\mathrm{PEI} / \alpha-\mathrm{PMo}_{12}\right)_{n}(n=20)$, and in $(\mathrm{C})$, substrates $1=\left\{\mathrm{PEI} /(\mathrm{PSS} / \mathrm{MB})_{n}\right\}(n=20)$ and $4=$ single monolayer PEI are shown.

multilayer films in antibacterial materials. Extended studies on antibacterial activity of $\left\{\mathrm{PEI} /(\mathrm{POMs} / \mathrm{MB})_{n}\right\}$ multilayers against other bacterial species are needed.

\section{Experimental Section}

Layer-by-layer assembly

The substrates were treated according to the literature method [28], which made their surface become hydrophilic.
Then the hydrophilized substrates were immersed in $2 \times$ $10^{-2} \mathrm{~mol} \mathrm{~L}^{-1}$ poly(ethylenimine) (PEI) solution for $20 \mathrm{~min}$, followed by washing with deionized water. After washing, a nitrogen stream was blown over the film surfaces until the adhering water layers were completely removed. The PEIcoated substrates then were alternately dipped into $1 \times 10^{-3}$ mol L ${ }^{-1} \mathrm{POM}\left(\alpha-\mathrm{SiW}_{12}\right.$ or $\left.\alpha-\mathrm{PMo}_{12}\right)$ aqueous solution and $1 \times 10^{-5} \mathrm{~mol} \mathrm{~L}^{-1} \mathrm{MB}$ aqueous solution for $20 \mathrm{~min}$, also rinsed with deionized water and dried in a nitrogen stream after each dipping. $2 \times 10^{-2} \mathrm{~mol} \mathrm{~L}^{-1}$ poly(styrenesulfonate) (PSS) was used to prepare $\left\{\mathrm{PEI} /(\mathrm{PSS} / \mathrm{MB})_{n}\right\}$ multilayer films for the antibacterial active test.

\section{Characterization}

UV/Vis spectra were recorded on a $756 \mathrm{CRT}$ UV/Vis spectrophotometer made in Shanghai, China. AFM images were obtained by using a Digital Nanoscope IIIa instrument operating in the tapping mode with silicon nitride tips. XPS analyses were performed on a Thermo Escalab 250 spectrometer with an $\mathrm{Mg} K_{\alpha}(1253.6 \mathrm{eV})$ achromatic X-ray source. A CHI 600 electrochemical workstation connected to a digital-586 personal computer was used for controlling the electrochemical measurements and for data collection. A conventional three-electrode system was used, with an ITO electrode or $\left\{\mathrm{PEI} /(\mathrm{POMs} / \mathrm{MB})_{n}\right\}$ multilayer films coated on an ITO electrode as working electrodes, platinum foil as a counter electrode and SCE as a reference electrode, in $\mathrm{pH}=$ 4.7 buffer solution.

\section{Antibacterial testing}

The antibacterial activities of the $\left\{\mathrm{PEI} /(\mathrm{POM} / \mathrm{MB})_{n}\right\}$ films and other contrastive multilayer films against the bacteria $E$. coli were carefully assessed by an optical method. A typical test is as follows: E. coli were inoculated in an aqueous medium of $1 \%$ peptone, $0.5 \%$ yeast extract, and $0.5 \% \mathrm{NaCl}$, and the inoculation was conducted at $37{ }^{\circ} \mathrm{C}$ for $24 \mathrm{~h}$ with shaking. The obtained bacterial suspension was then diluted by 100 times with the same peptone solution. Nutrient agar (typetone $1 \%$, yeast extract $0.5 \%, \mathrm{NaCl}$ $0.5 \%$, agar $1 \%, \mathrm{H}_{2} \mathrm{O}$ ) for antibacterial activity determination was autoclaved at $121{ }^{\circ} \mathrm{C}$ for at least $20 \mathrm{~min}$, then poured into autoclaved circular Petri dishes (90 $\mathrm{mm}$ dia.) and cooled to form a thick slab. Then $0.1 \mathrm{~mL}$ diluted bacterial suspension was spread uniformly on the surface of the nutrient agar slab. Meanwhile, all needed multilayer film substrates $\left\{\mathrm{PEI} /(\mathrm{POMs} / \mathrm{MB})_{n}\right\}(n=20),(\mathrm{PEI} / \mathrm{POMs})_{n}(n=$ $20), \mathrm{PEI} /(\mathrm{PSS} / \mathrm{MB})_{n}(n=20)$ and monolayer PEI were prepared. Then autoclaved sample substrates were placed in the center of the slabs. The antibacterial efficacy was evaluated with naked eye after the Petri dishes were incubated at $37{ }^{\circ} \mathrm{C}$ for $24 \mathrm{~h}$ to see whether colonies were visible or not. Optical photographs of the inhibition zones were recorded by camera. For the assessment of the survival rate 
of $E$. coli, the same amounts of nutrient agar from inhibition zones and non-inhibition zones were taken out, colored with crystal violet and diluted with the same volumes of water, and then the resulting suspensions were put under the optical microscope to account for the survival rate of E. coli.
Acknowledgement

This work was supported by the National Natural Science Foundation of China (20671016) and the Program for Changjiang Scholars and Innovative Research Team in University.
[1] C. L. Hill, Chem. Rev. 1998, 98, 1-2.

[2] V. Kozhevniko, Chem. Rev. 1998, 98, 171-198.

[3] M. T. Pope, A. Müller, Angew. Chem. 1991, 103, 5670; Angew. Chem., Int. Ed. Engl. 1991, 30, 34-38.

[4] E. Coronado, C. J. Gómez-García, Chem. Rev. 1998, 98 , $273-296$.

[5] D. Volkmer, A. D. Chesne, D. G. Kurth, H. Schnablegger, P. Lehmann, M. J. Koop, A. Müller, J. Am. Chem. Soc. 2000, 122, $1995-1998$.

[6] I. Moriguchi, J.H. Fendler, Chem. Mater. 1998, 10, $2205-2211$.

[7] A. Kuhn, F. C. Anson, Langmuir 1996, 12, 5481 - 5488.

[8] I. Ichinose, H. Tagawa, S. Mizuki, Y. Lvov, T. Kunitake, Langmuir 1998, 14, 187-192.

[9] H.E. Katz, G. Sheller, T. M. Putvinski, M. L. Shilling, W. L. Wilson, C.E.D. Chidsey, Science 1991, 254, $1485-1487$.

[10] M. Ferreira, J.H. Cheung, M.F. Rubner, Thin Solid Films 1994, 244, 806-809.

[11] A.C. Fou, O. Onisuka, M. Ferreira, M.F. Rubner, J. Appl. Phys. 1996, 79, $7501-7509$.

[12] L. Xu, H. Y. Zhang, E. B. Wang, A. G. Wu, Z. Li, Mater. Chem. Phys. 2002, 77, 484-488.

[13] H. Y. Ma, J. Peng, Y. H. Chen, Y. H. Feng, E. B. Wang, J. Solid State Chem. 2004, 177, 3333 - 3338.

[14] G. G. Gao, L. Xu, W. J. Wang, J. Phys. Chem. B 2005 , 109, 8948-8953.

[15] S. Q. Liu, D. G. Kurth, H. Möhwald, D. Volkmer, $A d v$. Mater. 2002, 14, 225-228.
[16] M. Jiang, E. B. Wang, G. Wei, L. Xu, Z. Li, J. Colloid Interface Sci. 2004, 275, 596-600.

[17] S.Q. Liu, H. Möhwald, D. Volkmer, D. G. Kurth, Langmuir 2006, 22, 1949 - 1951.

[18] L. Cheng, S. J. Dong, J. Electrochem. Soc. 2000, 147, $606-612$.

[19] L. Cheng, J. A. Cox, Chem. Mater. 2002, 14, 6-8.

[20] S. Y. Gao, R. Cao, C. P. Yang, J. Colloid Interface Sci. 2008, 324, 156- 166.

[21] D. L. Nelson, M. M. Cox, Lehninger Principles of Biochemistry, $3^{\text {rd }}$ ed., W. H. Freeman, New York, 2000.

[22] W. Tang, H. Xu, R. Kopelman, M. A. Philbert, Photochem. Photobiol. 2005, 81, 242-249.

[23] M. Wainwright, Dyes and Pigments 2008, 76, $582-$ 589.

[24] M. Wainwright, K. B. Crossley, J. Chemother. 2002, 14, $431-443$.

[25] L.S. Peloi, R. R. S. Soares, C.E. G. Biondo, V.R. Souza, N. Hioka, E. Kimura, J. Biosci. 2008, 33, 231 237.

[26] Y.H. Feng, Z. G. Han, J. Peng, J. Lu, B. Xue, L. Li, H. Y. Ma, E. B. Wang, Mater. Lett. 2006, 60, $1588-$ 1593.

[27] Y. M. Kong, L. N. Pan, J. Peng, B. Xue, J. Lu, B. X. Dong, Mater. Lett. 2007, 61, 2393 - 2397.

[28] F. Caruso, D. G. Kurth, D. Volkmer, M. J. Koop, A. Müller, Langmuir 1998, 14, 3462 - 3465. 